\title{
EchoGéo
}

$31 \mid 2015$

Glocal Ethiopia

\section{Au-delà du singulier}

Jean-Louis Chaléard

\section{OpenEdition}

Journals

Édition électronique

URL : https://journals.openedition.org/echogeo/14204

DOI : 10.4000/echogeo.14204

ISSN : 1963-1197

\section{Éditeur}

Pôle de recherche pour l'organisation et la diffusion de l'information géographique (CNRS UMR 8586)

Référence électronique

Jean-Louis Chaléard, « Au-delà du singulier », EchoGéo [En ligne], 31 | 2015, mis en ligne le 10 avril 2015, consulté le 01 août 2021. URL : http://journals.openedition.org/echogeo/14204 ; DOI : https:// doi.org/10.4000/echogeo.14204

Ce document a été généré automatiquement le 1 août 2021

EchoGéo est mis à disposition selon les termes de la licence Creative Commons Attribution - Pas d'Utilisation Commerciale - Pas de Modification 4.0 International (CC BY-NC-ND) 


\title{
Au-delà du singulier
}

\author{
Jean-Louis Chaléard
}

1 La nouvelle livraison d'ÉchoGéo est consacrée en grande partie à l'Éthiopie. Des dossiers de notre revue ont déjà été centrés sur un pays (Belgique, Turquie...). L'intérêt d'une telle approche est bien sûr de permettre d'entrer en profondeur dans la réalité d'un territoire et d'en analyser les différentes facettes. En même temps, la thématique du dossier Sur le champ, les réflexions issues des autres rubriques, nous amènent à dépasser le cas singulier pour élargir notre pensée.

2 Le dossier de la rubrique Sur le champ, « Glocal-Ethiopia - Échelles et positionnement des pouvoirs » est à la croisée de plusieurs questions générales, touchant aux relations du global et du local et aux méthodes d'approche d'une question qui concerne la plupart des disciplines de sciences sociales. Dans leur introduction au dossier, M. Bridonneau et S. Planel insistent sur l'analyse des relations entre local et global pour comprendre l'articulation des différentes échelles et les pouvoirs en Éthiopie. En effet, le pays s'est lancé depuis quelques années dans une ouverture sur l'extérieur qui l'insère dans la mondialisation. Outre la libéralisation des marchés, des réformes diverses (qui souvent l'accompagnent) ont été mises en place, comme la décentralisation. Le dossier permet de s'interroger sur les évolutions les plus récentes, à partir d'études fines de terrain, localisées dans différentes régions du pays. Partout le poids du pouvoir central, malgré la décentralisation, est pesant. C'est dans le jeu entre la mondialisation, le pouvoir d'État, les nouvelles perspectives offertes par la décentralisation que se produisent les dynamiques locales.

3 Chaque texte aborde un volet significatif de la nouvelle réalité éthiopienne. D. Chinigo et E. Fantini en s'intéressant aux politiques foncières récentes mises en place par le gouvernement éthiopien pour promouvoir la commercialisation agricole, relèvent les contradictions entre la recherche d'une consolidation de leur pouvoir par les élites et la libéralisation économique et politique à travers l'étude des réformes dans la zone West Arsi. J. Nyssen et al. proposent, à partir d'une analyse dans le nord montagneux, une réflexion sur les facteurs du changement écologique du pays, à la fois endogènes et exogènes. Toujours dans le nord, R. Lefort met en évidence les recompositions sociales associées au développement de nouvelles cultures commerciales dans un bourg de la 
région Amhara, insistant sur les différenciations sociales croissantes entre des agriculteurs qui réussissent (les nouveaux «koulaks») et des phénomènes de prolétarisation. G. Pinault étudie le commerce du bétail des Somali et souligne que la mondialisation donne à l'État une occasion de mieux maîtriser un territoire périphérique et ses ressources, même s'il se heurte à la résistance d'un système pluriséculaire pour lequel le bétail demeure une ressourcé inaliénable. J.-N. Bach analyse la façon dont l'islam radical est utilisé par le pouvoir en place pour contrôler les musulmans éthiopiens et maîtriser les résistances qui sont apparues depuis 2011, contribuant au décryptage des modes de gouvernement actuels en Éthiopie. G. Blanc et M. Bridonneau montrent comment la mise en patrimoine (ici, l'inscription sur la Liste du patrimoine mondial de l'Humanité de la ville de Lalibela et des montagnes du Semèn) fait émerger une élite de « consultants ", qui participe à l'ancrage du local dans la sphère internationale, à l'ouverture du pays et à la consolidation du pouvoir éthiopien. Poursuivant la réflexion dans le champ culturel, C. Josse-Durand décrit, à partir du musée Konso, premier musée ethnographique au sud de l'Éthiopie, les détournements et récupérations, par le gouvernement et des «courtiers en développement » locaux, d'un projet né de la coopération culturelle.

4 L'unité du dossier vient largement de l'approche, insistant sur le jeu entre les échelles comme méthode d'appréhension des dynamiques. Les cas étudiés, avec les sensibilités disciplinaires différentes des auteurs, permettent d'appréhender la complexité des situations et d'approfondir les réflexions sur le glocal. La variété des thèmes abordés montre que les changements affectent toutes les composantes sociales et régionales $\mathrm{du}$ pays. Émergent de nouvelles arènes politiques, de nouvelles figures dynamiques (entrepreneurs, courtiers, consultants, etc.) et apparaissent des groupes marginalisés (musulmans contestataires, nouveaux prolétaires...). Mais sur le fond, c'est la redéfinition du pouvoir d'État dans son rapport d'une part à la société et au territoire éthiopiens, d'autre part au monde qui nous est surtout révélée tout au long de ce dossier.

5 L'article de la rubrique Sur l'image, nous propose un retour à Lalibela. La rencontre de M. Bridonneau avec M.-L. Derat et C.Bosc-Tiessé, historiennes, permet de faire ressortir le grand intérêt d'une cartographie du site. La carte, entre autres, rend compte de manière synthétique des informations collectées. Elle est un outil indispensable à la compréhension. Bien plus, face aux transformations liées à l'extension urbaine, elle participe à la conservation d'une mémoire des lieux et révèle des enjeux spatiaux et historiques, allant à l'encontre d'une lecture essentialiste du site. Instrument privilégié du géographe, la carte peut être aussi un élément d'analyse essentiel pour des chercheurs d'autres disciplines.

6 La rubrique Sur l'écrit propose une lecture croisée de l'ouvrage d'U. Braukämper : A History of the Hadiyya in Sutherne Ethiopia publié en 2012 dans sa version anglaise. Cet ouvrage est l'occasion pour une géographe (S. Planel) et un anthropologue (T. Osmond) de confronter leur lecture des apports de l'œuvre et leur approche de l'ethnie. Au-delà, il permet une réflexion sur les concepts utilisés en sciences sociales et l'intérêt de la confrontation de regards disciplinaires différents.

7 L'entretien de M. Bridonneau avec J. Chambrillon dans la rubrique Sur le métier complète le dossier sur l'Éthiopie. Il relate l'itinéraire d'un géographe passé au commerce du café sur les hautes terres éthiopiennes. Reliant son métier à sa formation, 
l'interviewé souligne l'intérêt de la démarche et des savoir-faire des géographes dans la recherche des cafés et l'identification des terroirs.

Deux textes nouveaux viennent enrichir la rubrique Sur le vif. Si aucun n'aborde l'Éthiopie, ils portent sur l'Afrique et sur des questions qui touchent au local et au mondial. L'un est centré sur l'épidémie d'Ebola en Guinée, l'autre sur les évènements récents liés à la montée du radicalisme islamique au Niger. L'ampleur de l'épidémie actuelle de la maladie à virus Ebola a inquiété par sa soudaineté et sa virulence. $\mathrm{H}$. Simon-Lorière et B. Lysaniuk font le point sur la diffusion de l'épidémie et, partant d'une analyse qui prend en compte le complexe pathogène d'Ebola, l'histoire récente et les organisations sociales, ils émettent des hypothèses crédibles pour expliquer la maladie. Au-delà, ils montrent l'intérêt d'une démarche géographique dans la compréhension de la diffusion de cette épidémie. L'article d'E. Grégoire illustre un des aspects de la montée de l'intégrisme islamiste en Afrique qui touche de nombreux pays. Le Niger est à la fois sous la menace des groupes djihadistes installés à ses frontières et en proie à une série de problèmes intérieurs. Pris entre la crise malienne, le désordre qui règne en Lybie, le conflit armé qui a débuté contre Boko Haram dans le sud, il demeure dans un équilibre fragile. Les manifestations de janvier 2015, qui ont permis de prendre conscience de la progression de l'islam radical dans le pays, soulignent la conjonction des dangers extérieurs et intérieurs.

9 La question du sous-développement se retrouve en toile de fond dans l'ensemble des textes présentés dans ce numéro d'EchoGéo. Sous-développement qui ne permet guère d'offrir de perspectives d'avenir à la jeunesse nombreuse du Niger, qui favorise l'expansion des maladies et rend plus aléatoire leur traitement en Afrique de l'Ouest, et dont essaie de sortir l'Éthiopie avec difficulté. Voici un autre thème de réflexion finalement abordé dans ce numéro. 